\title{
Corrigendum: Prevalence of Common Mental Disorders in South Asia: A Systematic Review and Meta-Regression Analysis
}

\author{
Sadiq Naveed ${ }^{1}$, Ahmed Waqas ${ }^{2 *}$, Amna Mohyud Din Chaudhary ${ }^{3}$, Sham Kumar ${ }^{4}$, \\ Noureen Abbas ${ }^{5}$, Rizwan Amin ${ }^{6}$, Nida Jamil ${ }^{7}$ and Sidra Saleem ${ }^{4}$ \\ ${ }^{1}$ Department of Child Psychiatry, Kansas University Medical Center, Kansas City, KS, United States, ${ }^{2}$ Institute of Population \\ Health, University of Liverpool, Liverpool, United Kingdom, ${ }^{3}$ Nishtar Medical University, Multan, Pakistan, ${ }^{4}$ Dow Medical \\ College, Karachi, Pakistan, ${ }^{5}$ FMH College of Medicine and Dentistry, Lahore, Pakistan, ${ }^{6}$ King Edward Medical University, \\ Lahore, Pakistan, ${ }^{7}$ Fatima Jinnah Medical University, Lahore, Pakistan
}

Keywords: psychiatric illness, South Asia, prevalence, epidemiology, common mental disorders

\section{A Corrigendum on}

Prevalence of Common Mental Disorders in South Asia: A Systematic Review and Meta-Regression Analysis

by Naveed, S., Waqas, A., Chaudhary, A. M. D., Kumar, S., Abbas, N., Amin, R., et al. (2020). Front. Psychiatry 11:573150. doi: 10.3389/fpsyt.2020.573150

\section{OPEN ACCESS}

Edited and reviewed by: Wulf Rössler,

Charité - Universitätsmedizin Berlin, Germany

*Correspondence: Ahmed Waqas

ahmed.waqas@liverpool.ac.uk

Specialty section:

This article was submitted to Public Mental Health,

a section of the journal

Frontiers in Psychiatry

Received: 02 September 2020 Accepted: 14 September 2020 Published: 20 November 2020

Citation:

Naveed S, Waqas A, Chaudhary AMD, Kumar S, Abbas N, Amin R, Jamil N and Saleem S (2020) Corrigendum:

Prevalence of Common Mental Disorders in South Asia: A Systematic Review and Meta-Regression Analysis. Front. Psychiatry 11:602062. doi: 10.3389/fpsyt.2020.602062
In the original article, there was a mistake in Table 1 "Pooled prevalence of mental disorders in South Asia" as published. Prevalence estimates of five of the psychiatric disorders were wrongly formatted with misplaced decimal points. The corrected Table 1 "Pooled prevalence of mental disorders in South Asia" appears below.

In the original article, there was a mistake in Table 3 "Subgroup analyses presenting several factors associated with the prevalence of CMDs in included studies" as published. Prevalence estimates for subgroups of sampling methods were wrongly formatted. The corrected Table 3 "Subgroup analyses presenting several factors associated with the prevalence of CMDs in included studies" appears below.

In the original article, there was an error. Prevalence estimates for panic disorder was wrongly formatted with misplaced decimal points in the results section of abstract and main text.

A correction has been made to the Research section, Paragraph Number 2:

We assessed the pooled prevalence for 17 different mental disorders over a period of 10 years. All the outcomes presented significant heterogeneity ranging from $0 \%$ to $99.79 \%$ for stimulant use and alcohol abuse, respectively. The prevalence of depressive symptoms was reported in 135 studies $\left(I^{2}\right.$ $=99.53 \%$ ) yielding a prevalence of $26.4 \%$ among 173,449 participants. Alcohol abuse was reported in 43 studies yielding a prevalence of $12.9 \%\left(8.8 \%-18.6 \%, I^{2}=99.79 \%, \mathrm{n}=107893\right)$; anxiety $25.8 \%$ $\left(19.4 \%\right.$ to $\left.33.5 \%, I^{2}=99.57 \%, \mathrm{n}=70,058\right)$; tobacco smoking $18.6 \%\left(14.3 \%\right.$ to $24 \%, I^{2}=99.58 \%, \mathrm{n}=$ $84965)$; PTSD $17.2 \%\left(11 \%\right.$ to $\left.25.9 \%, I^{2}=99.55 \%, \mathrm{n}=42298\right)$; mixed anxiety and depression $28.4 \%$ ( $13.9 \%$ to $\left.49.3 \%, I^{2}=99.41 \%, \mathrm{n}=11102\right)$; suicidal behaviors $6.4 \%\left(3.1 \%\right.$ to $12.4 \%, I^{2}=99.41 \%, \mathrm{n}$ $=25043)$; misuse of opiates $0.8 \%\left(0.2 \%\right.$ to $\left.2.5 \%, I^{2}=99.06 \%, \mathrm{n}=37304\right)$; tobacco chewing $21.0 \%$ $\left(14.0 \%\right.$ to $\left.30.3 \%, I^{2}=98.49 \%, \mathrm{n}=10586\right)$; use of cannabis $3.4 \%\left(1.5 \%\right.$ to $7.3 \%, I^{2}=97.48 \%, \mathrm{n}$ $=10977)$; GAD $2.9 \%$ (0.3\% to $\left.26.5 \%, I^{2}=99.57 \%, \mathrm{n}=70058\right)$; bipolar disorder $0.6 \%(0.3 \%$ to $\left.1.0 \%, I^{2}=78.21 \%, \mathrm{n}=7197\right)$; IV drug abuse $2.5 \%\left(0.1 \%\right.$ to $\left.32.1 \%, I^{2}=99.72 \%, \mathrm{n}=15049\right)$; Panic disorder $1.3 \%\left(0.5 \%\right.$ to $\left.3.4 \%, I^{2}=95.43 \%, \mathrm{n}=28087\right)$; stimulant use $0.9 \%\left(0.5 \%\right.$ to $1.6 \%, I^{2}=0 \%$, 
TABLE 1 | Pooled prevalence of mental disorders in South Asia.

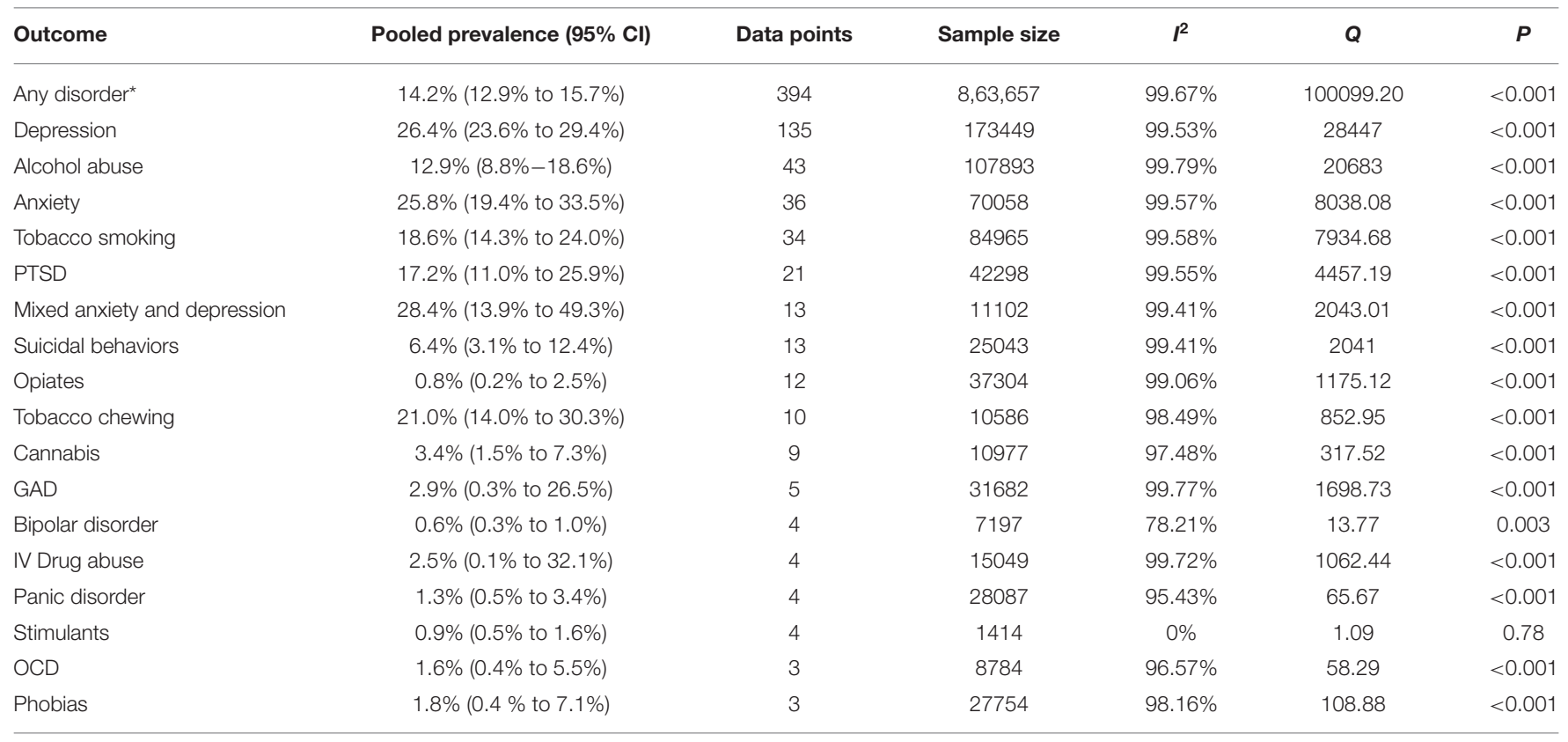

${ }^{*}$ Pooled estimate after adjusting for publication bias $=11.31 \%$ (10.05\% to $\left.12.69 \%\right)$.

TABLE 3 | "Subgroup analyses presenting several factors associated with the prevalence of CMDs in included studies".

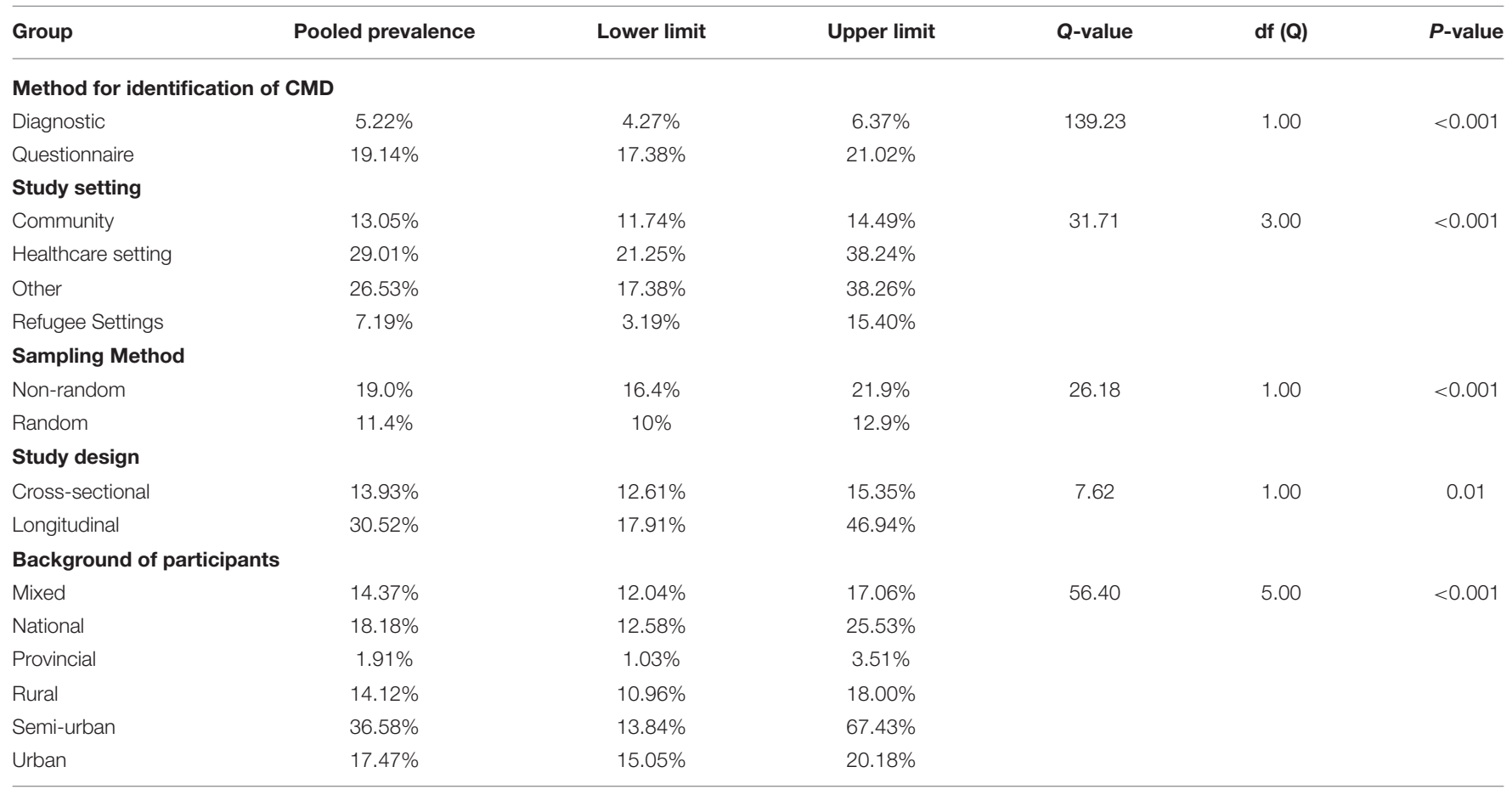

$\mathrm{n}=1414)$; OCD $1.6 \%\left(0.4 \%\right.$ to $\left.5.5 \%, I^{2}=96.57 \%, \mathrm{n}=8784\right)$ and phobic disorders $1.8 \%\left(0.4 \%\right.$ to $\left.7.1 \%, I^{2}=98.16 \%, \mathrm{n}=27754\right)$. Supplementary Figures 1-12 represent the forest plots for the above-mentioned disorders.

In the original article, there was an error. Prevalence estimates for panic disorder was wrongly formatted with misplaced decimal points in the results section of abstract and main text.

A correction has been made to the abstract:

A prevalence of depressive symptoms was $26.4 \%$ among 173,449 participants, alcohol abuse was $12.9 \%(\mathrm{n}=107,893)$; anxiety $25.8 \%(\mathrm{n}=70,058)$; tobacco smoking $18.6 \%(\mathrm{n}=84,965)$; 
PTSD 17.2\% ( $\mathrm{n}=42,298)$; mixed anxiety and depression $28.4 \%$ ( $\mathrm{n}=11,102)$; suicidal behaviors $6.4 \%(\mathrm{n}=25,043)$; misuse of opiates $0.8 \%(n=37,304)$; tobacco chewing $21.0 \%(n=10,586)$; use of cannabis $3.4 \%(n=10,977)$; GAD 2.9\% $(n=70,058)$; bipolar disorder $0.6 \%(\mathrm{n}=7,197)$; IV drug abuse $2.5 \%(\mathrm{n}=$ $15,049)$; panic disorder $1.3 \%(\mathrm{n}=28,087)$; stimulant use $0.9 \%$ $(\mathrm{n}=1,414)$; OCD $1.6 \%(\mathrm{n}=8,784)$ and phobic disorders $1.8 \%(\mathrm{n}$ $=27,754)$.

The authors apologize for these errors and state that this does not change the scientific conclusions of the article in any way. The original article has been updated.

Copyright $\odot 2020$ Naveed, Waqas, Chaudhary, Kumar, Abbas, Amin, Jamil and Saleem. This is an open-access article distributed under the terms of the Creative Commons Attribution License (CC BY). The use, distribution or reproduction in other forums is permitted, provided the original author(s) and the copyright owner(s) are credited and that the original publication in this journal is cited, in accordance with accepted academic practice. No use, distribution or reproduction is permitted which does not comply with these terms. 